\title{
Basal Domain of the Epithelium
}

National Cancer Institute

\section{Source}

National Cancer Institute. Basal Domain of the Epithelium. NCI Thesaurus. Code C32185.

The free part of the epithelium that faces the interior surface of the lumen of an organ or towards the interstitium. 